\title{
Effects of TJ-35 (Shigyaku-san) on Gastric Mucosal Injury Induced by Ischemia-Reperfusion and Its Oxygen-Derived Free Radical-Scavenging Activities
}

\author{
Toshikazu YoshiKawa, ${ }^{*}$ Shuji Takahashi, Hiroshi IchIKawa, \\ Hirohisa TAKANO, Naohiro TASAKI, Mitsunori YASUDA, \\ Yuji NAITO, Toru TANIGAWA, and Motoharu Kondo \\ First Department of Internal Medicine, Kyoto Prefectural \\ University of Medicine, Kyoto 602, Japan \\ (Received January 11, 1991)
}

\begin{abstract}
Summary We investigated the effects of TJ-35 (Shigyaku-san) on gastric mucosal injury induced by ischemia-reperfusion in rats; and using the electron spin resonance (ESR) spin trapping method, we also assessed its oxygen-derived free radical-scavenging activities. The increase in mucosal lesions and in thiobarbituric acid-reactive substances (as an index of lipid peroxidation) was significantly inhibited by the oral administration of $500 \mathrm{mg} / \mathrm{kg}$ of TJ-35; and in addition, TJ-35 demonstrated superoxide and hydroxyl radical-scavenging activities in vitro. These results suggest the possibility that the effects of TJ-35 on gastric mucosal injury induced by ischemia-reperfusion may be the result of its free radical-scavenging activities.
\end{abstract}

Key Words: TJ-35 (Shigyaku-san), gastric mucosal injury, ischemiareperfusion, oxygen-derived free radicals, ESR spin trapping method

In recent years, while oxygen-derived free radicals have been reported to be closely involved in many medicobiologic problems such as inflammation $[1,2]$, cancer $[3,4]$, atherosclerosis $[5,6]$, ischemia-reperfusion injury [7-9], shock [10, $11]$, and so on, the prevention of disease and possibilities of treatment by enhancement of the antioxidant capacity of the host has been vigorously researched. Also considerable attention has centered on the antioxidant activities of various drugs, for example, anti-allergic drugs [12, 13], non-steroidal antiinflammatory drugs $[14,15]$, traditional Kampo medicines [16-18], and so on. Additionally, in various experimental gastric ulcer models $[9,19-21]$, the involvement of oxygen-

\footnotetext{
*To whom correspondence should be addressed.
} 
derived free radicals and lipid peroxidation as mediators in the development of mucosal injury has been suggested; and the inhibitory effects of superoxide dismutase (SOD), catalase, and a variety of drugs with antioxidant activities have been investigated. We previously showed [9] that gastric mucosal injury can be produced, and thiobarbituric acid (TBA)-reactive substances in the gastric mucosa significantly increased, after reoxygenation following $30 \mathrm{~min}$ of gastric mucosal ischemia and that both of these changes can be clearly and significantly inhibited by preadministration of SOD and catalase. These results suggest that active oxygens and lipid peroxidation may play an important role in the formation of gastric mucosal injury induced by ischemia-reperfusion.

In this study, based on present research [16-18] that has been directed toward the excellent antioxidant properties of traditional Kampo medicines, we investigated the effects of TJ-35 (Shigyaku-san), which is clinically useful for the treatment of gastritis and peptic ulcers, on gastric mucosal injury induced by ischemiareperfusion in rats. Further, we examined the oxygen-derived free radicalscavenging activities in vitro of this medicine.

\section{MATERIALS AND METHODS}

In vivo study. After an 18-h fast, laparotomy was performed on SpragueDawley strain male rats under pentobarbital anesthesia $(25 \mathrm{mg} / \mathrm{kg})$. The celiac artery was then blocked with a clamp for $30 \mathrm{~min}$, after which reperfusion was allowed for $60 \mathrm{~min}$ by opening of the clamp. Then the blood was drained, the stomach extirpated, and the gastric mucosa carefully examined macroscopically and microscopically. The extent of gastric mucosal lesions was expressed by the total area of the erosions [9], and TBA-reactive substances in the gastric mucosa measured by the method of Ohkawa et al. [22] as an index of lipid peroxidation. TJ-35 raw powder extract (Tsumura Co., Ltd., Tokyo) was dissolved in $1 \mathrm{ml}$ of distilled water; and 50,250 , and $500 \mathrm{mg} / \mathrm{kg}$ were orally administered one hour prior to the start of ischemia. The control group was administered $1 \mathrm{ml}$ of distilled water. The gastric mucosal blood flow was measured with a Laser Doppler Blood Flowmeter (Advance Co., Ltd., Tokyo) [23].

In vitro study. Superoxide and hydroxyl radical-scavenging activities were measured by an electron spin resonance (ESR) assay using 5,5-dimethyl-1pyrroline-N-oxide (DMPO, Sigma Chemical Co., St. Louis, MO) as a spin trap. A JEOL-JES-FR80 (JEOL, Akishima, Japan) was used as the ESR instrument.

Superoxide-scavenging activity was measured by following the ESR spin trapping method previously reported [24]. In other words, the superoxide generated by the hypoxanthine (HX, Wako Pure Chemical Ind., Osaka)-xanthine oxidase (XO, Sigma) system was trapped by DMPO, and the rate of inhibition by TJ-35 of the resulting DMPO-OOH signal intensity was determined, and compared with that obtained with a standard human SOD (Nippon Kayaku Co., Ltd., Tokyo). For the actual measurements, $500 \mu \mathrm{M} \mathrm{HX}, 0.1 \mathrm{mM}$ diethylenetriaminepentaacetic 
acid (DETAPAC, Wako Pure Chemical Ind.), $100 \mathrm{~mm} \mathrm{DMPO,} \mathrm{and} \mathrm{test} \mathrm{sample}$ and $125 \mathrm{~mm}$ Tris- $\mathrm{HCl}$ buffer ( $\mathrm{pH}$ 7.4) were combined as final concentrations, XO was added, and the signal intensity was then measured $2 \mathrm{~min}$ later. The spectrometer settings were as follows: microwave power, $8 \mathrm{~mW}$; modulation frequency, $100 \mathrm{kHz}$; modulation amplitude, $0.1 \mathrm{mT}$; sweep time, $5 \mathrm{mT} / \mathrm{min}$; response time, $0.03 \mathrm{~s}$; receiver gain, $\times 1,000$.

For detection of hydroxyl radical-scavenging activity, we employed the ESR spin trapping method previously reported [25]. The hydroxyl radical produced by the Fenton reaction was trapped by DMPO, the resulting DMPO-OH signal intensity was measured, and the effect of TJ-35 on the signal intensity was examined. For the actual measurements, the test sample was added to a $50 \mathrm{mM}$ phosphate buffer solution containing $50 \mu \mathrm{M}$ ferrous sulfate, $0.1 \mathrm{~mm}$ DETAPAC, and $1 \mathrm{~mm}$ or $10 \mathrm{~mm}$ DMPO. Then hydrogen peroxide was added at a final concentration of $1 \mathrm{~mm}$, and the signal intensity measured 1 min later. The spectrometer settings were as follows: microwave power, $6 \mathrm{~mW}$; modulation frequency, $100 \mathrm{kHz}$, modulation amplitude, $0.1 \mathrm{mT}$; sweep time, $5 \mathrm{mT} / \mathrm{min}$; response time, $0.03 \mathrm{~s}$; receiver gain, $\times 100-\times 1,000$.

Data were given as mean \pm SEM. The significance of differences between groups was assessed by the Dunnet test.

\section{RESULTS}

\section{Effect of TJ-35 on gastric mucosal injury induced by ischemia-reperfusion}

The total area of erosions was $22.8 \pm 2.3 \mathrm{~mm}$ in the control group, $18.0 \pm 3.0$ $\mathrm{mm}$ in the $50 \mathrm{mg} / \mathrm{kg} \mathrm{TJ}-35$ group, $8.5 \pm 1.5 \mathrm{~mm}$ in the $250 \mathrm{mg} / \mathrm{kg}$ group, and $10.3 \pm$ $2.6 \mathrm{~mm}$ in the $500 \mathrm{mg} / \mathrm{kg}$ group, the latter two values representing significant reductions (Fig. 1). The concentration of TBA-reactive substances in the gastric mucosa was $0.39 \pm 0.02 \mathrm{nmol} / \mathrm{mg}$ protein in the naive-animal (normal) group, $0.52 \pm 0.02 \mathrm{nmol} / \mathrm{mg}$ protein in the control group, $0.50 \pm 0.04 \mathrm{nmol} / \mathrm{mg}$ protein in the $50 \mathrm{mg} / \mathrm{kg} \mathrm{TJ}-35$ group, $0.45 \pm 0.02 \mathrm{nmol} / \mathrm{mg}$ protein in the $250 \mathrm{mg} / \mathrm{kg}$ group, and $0.41 \pm 0.02 \mathrm{nmol} / \mathrm{mg}$ protein in the $500 \mathrm{mg} / \mathrm{kg}$ group. The control group value was increased significantly compared with the normal group one and that increase was significantly inhibited by $500 \mathrm{mg} / \mathrm{kg} \mathrm{TJ}-35$ (Fig. 2). Gastric mucosal blood flow decreased to about $10 \%$ of the normal value immediately after blockage of the celiac artery, and quickly recovered to its previous value by removal of the clamp 30 min later. The decrease in gastric mucosal blood flow after the clamping and prompt recovery of the blood flow following removal of the clamps were not influenced by the treatment with TJ-35 (Fig. 3).

\section{Superoxide and hydroxyl radical-scavenging activities}

A slight inhibition was observed in the DMPO-OOH signal with $0.01 \mathrm{mg} / \mathrm{ml}$ of TJ-35, and almost complete inhibition with $1 \mathrm{mg} / \mathrm{ml}$ (Fig. 4). If converted to SOD units, the water-soluble component of $1 \mathrm{mg}$ of TJ-35 was equivalent to 2.95

Vol. 10, No. 3, 1991 


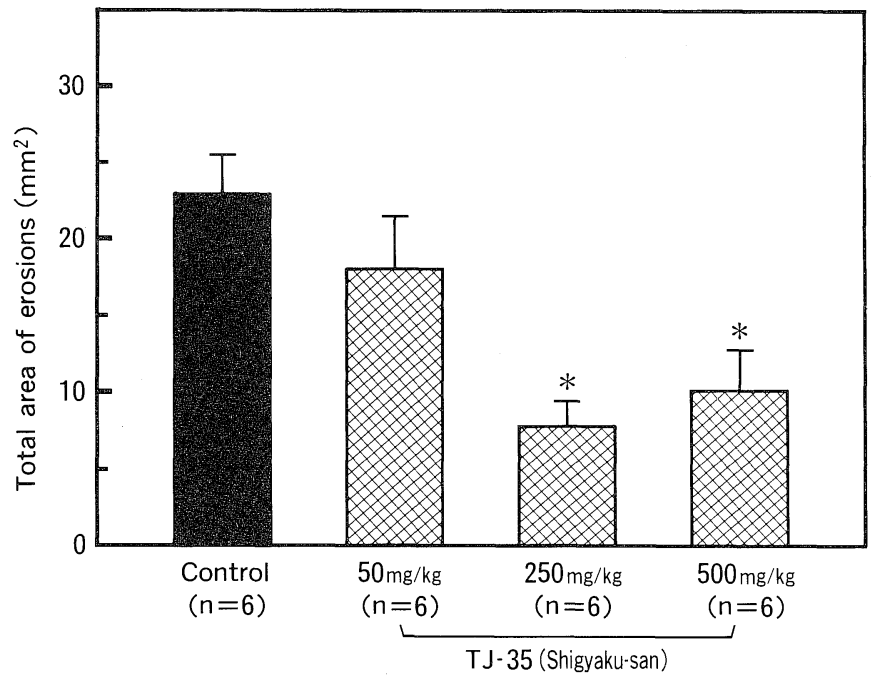

Fig. 1. Effect of TJ-35 on the total area of the erosions in the gastric mucosa induced by ischemia-reprefusion. Each value indicates the mean $\pm \mathrm{SE} .{ }^{*} p<0.05$ when compared with the value of the control group.

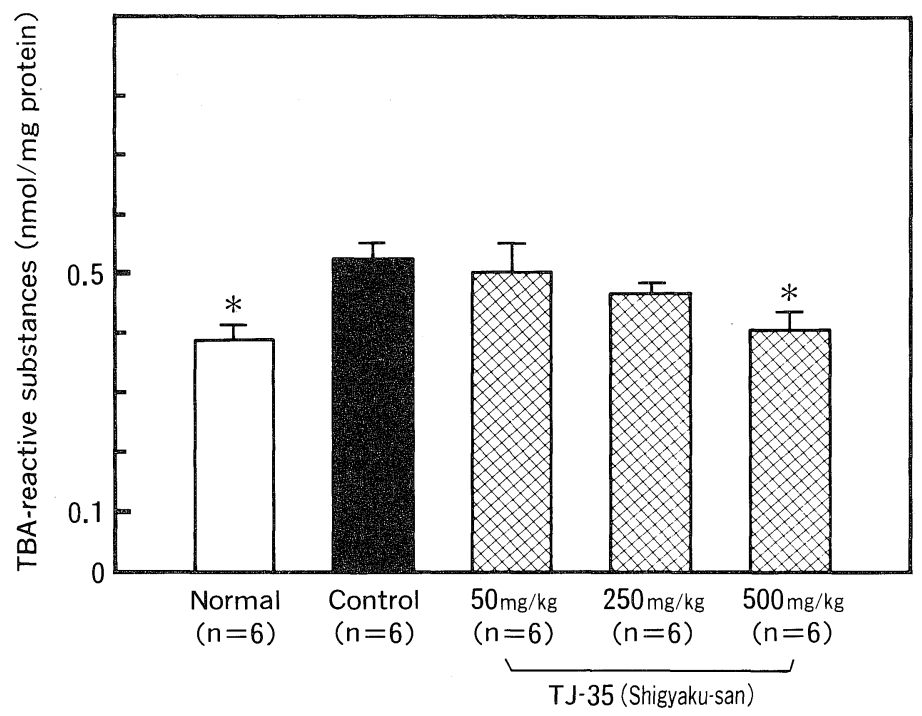

Fig. 2. Effect of TJ-35 on the increase in TBA-reactive substance level in the gastric mucosa induced by ischemia-reperfusion. Each value indicates the mean $\pm \mathrm{SE}$. ${ }^{*} p<0.05$ when compared with the value of the control group.

J. Clin. Biochem. Nutr. 


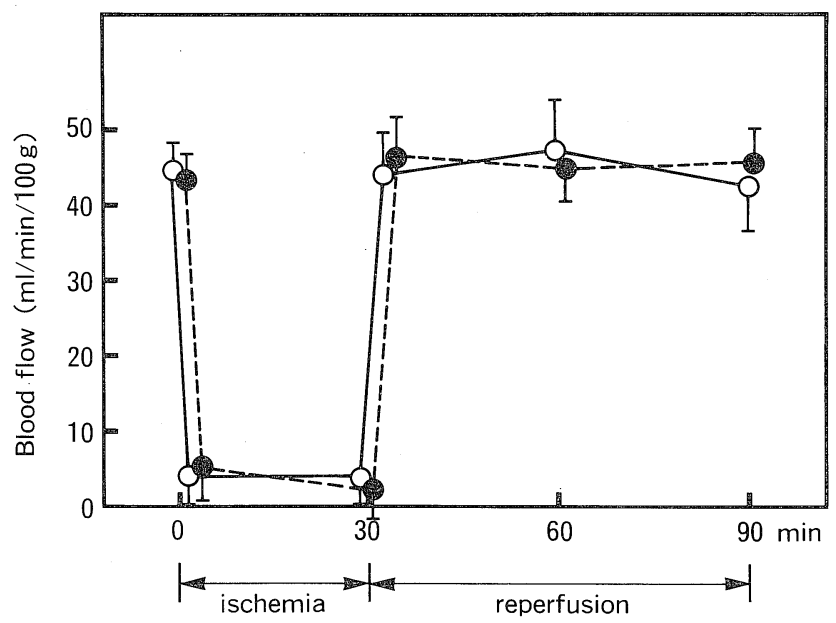

Fig. 3. Effect of TJ-35 on the gastric mucosal blood flow in the stomach. Open circles, control group; closed circles, TJ-35 group (500 mg/kg).

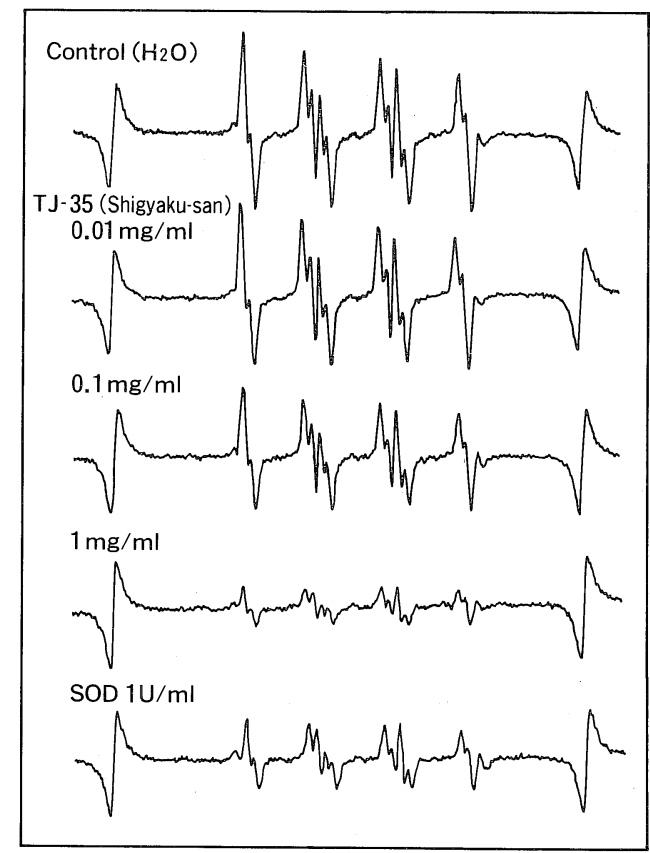

Fig. 4. Effect of TJ-35 and superoxide dismutase (SOD) on the DMPO-OOH signal obtained from the hypoxanthine-xanthine oxidase system.

Vol. 10, No. 3, 1991 


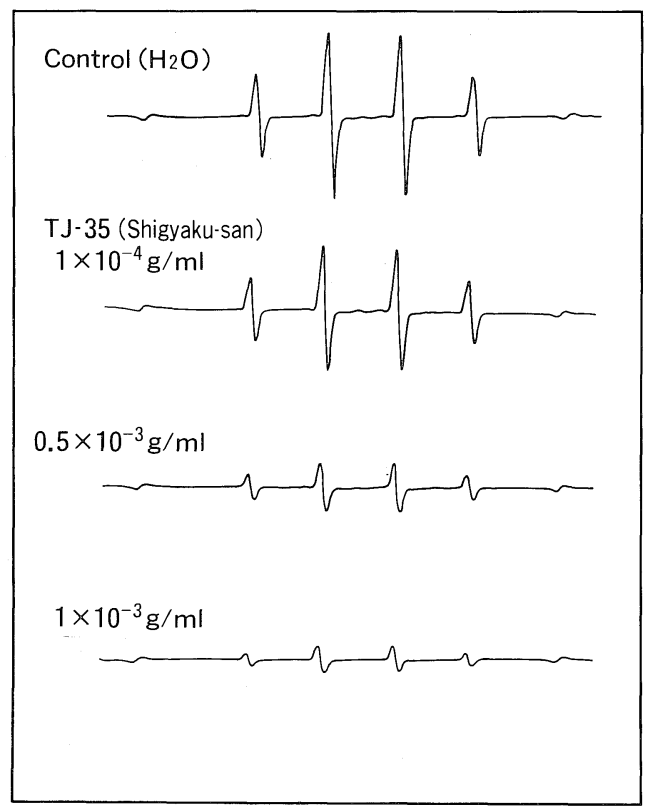

Fig. 5. Effect of TJ-35 on the DMPO-OH signal obtained from the Fenton reaction in the presence of $1 \mathrm{~mm}$ DMPO.

units of SOD. A slight inhibition was observed in the DMPO-OH signal with 0.1 $\mathrm{mg} / \mathrm{ml}$ of TJ-35, and almost complete inhibition with $1 \mathrm{mg} / \mathrm{ml}$ (Fig. 5). This inhibition was investigated with different DMPO concentrations ( 1 and $10 \mathrm{~mm}$ ) and was found to be the summation of inhibition based on competition with DMPO and inhibition of the Fenton reaction itself [25].

\section{DISCUSSION}

Many traditional Kampo medicines have been widely used in Japan as well as in China, but the active ingredients and mechanism of action of many of them are still unknown. Recently, pharmacologic studies on traditional Kampo medicines have intensified; and while the many and varied biological activities of these medicines are being clarified, there are also many reports [16-18] describing their oxygen-derived free radical-scavenging activities or antioxidant activities.

TJ-35 is a combination of four galenical drugs, i.e., bupleurum root, glycyrrhiza, peony root, and immature orange, and has various effects [26] such as improving mucosal blood flow, promoting mucous secretions, and inhibiting acid secretion. The possibility that TJ-35 showed an inhibitory effect on gastric mucosal injury induced by ischemia-reperfusion partly through these effects was also considered, but it did not have an effect on changes in blood flow caused by ischemia-reperfusion. Furthermore, in this model acid secretion itself is inhibited 
during ischemia-reperfusion [27]. Therefore, it is difficult to conceive of these as its main effects. Rather it is possible that the superoxide and hydroxyl radicalscavenging activities confirmed in vitro or some antioxidant activities of TJ-35 may have functioned effectively to reduce the injury. Peony root is said to contain tannins, substances that have various effects [17] such as superoxide-scavenging activity, lipid peroxidation inhibition, and lipoxygenase inhibition. Bupleurum root and immature orange contain flavonoids, a group of naturally occurring, benzo- $\gamma$-pyrone derivatives with low molecular weights. Many flavonoids are strong free radical scavengers and antioxidants [28, 29]. Moreover, glycyrrhizin in glycyrrhiza and saikosaponins [30] in bupleurum root have an inhibitory effect on superoxide production by neutrophils. The various actions of these four galenical drugs and their interactions may have some beneficial roles in the prevention of gastric mucosal injury induced by ischemia-reperfusion.

An increasing number of reports suggests the efficacy of SOD or certain antioxidants against many experimental or clinical disorders. It is worthy of note that traditional Kampo medicines contain numerous ingredients, a considerable number of which possess strong antioxidant activities. Further chemical identification of Kampo medicines, crude drugs, and other natural products may be highly informative.

\section{REFERENCES}

1. Oyanagui, Y. (1976): Participation of superoxide anions at the prostaglandin phase of carrageenan foot-edema. Biochem. Pharmacol., 25, 1465-1472.

2. Yoshikawa, T. (1985): The increase of lipid peroxidation in rat adjuvant arthritis and its inhibition by superoxide dismutase. Biochem. Med., 33, 320-332.

3. Zimmerman, R., and Cerutti, P. (1984): Active oxygen acts as a promoter of transformation in mouse embryo $\mathrm{C} 3 \mathrm{H} / 10 \mathrm{~T} 1 / 2 / \mathrm{C} 18$ fibroblasts. Proc. Natl. Acad. Sci. U.S.A., 81, 20852087.

4. Hirota, N., and Yokoyama, T. (1981): Enhancing effect of hydrogen peroxide upon duodenal and upper jejunal carcinogenesis in rats. Gann, 72, 811-812.

5. Steinberg, D. (1984): A look back and a look ahead. Atherosclerosis, 3, 283-301.

6. Quinn, M.T., Parthasarathy, S., and Fong, L.G. (1987): Oxidatively modified low density lipoproteins. A potential role in recruitment and retention of monocytes/macrophages during atherogenesis. Proc. Natl. Acad. Sci. U.S.A., 84, 2995-2998.

7. Gardner, T.J., Stewart, J.R., and Casale, A.S. (1983): Reduction of myocardial ischemic injury with oxygen-derived free radical. Surgery, 94, 423-427.

8. Granger, D.N., Rutili, G., and McCord, J.M. (1981): Superoxide radicals in feline intestinal ischemia. Gastroenterology, 81, 22-29.

9. Yoshikawa, T., Ueda, S., Naito, Y., Takahashi, S., Oyamada, H., Morita, Y., Yoneta, T., and Kondo, M. (1989): Role of oxygen-derived free radicals in gastric mucosal injury induced by ischemia or ischemia-reperfusion in rats. Free Rad. Res. Comm., 7, 3-6.

10. Yoshikawa, T., Murakami, M., Seto, O., Kakimi, Y., Takemura, T., Tanigawa, T., Sugino, S., and Kondo, M. (1986): Effects of superoxide dismutase and catalase on endotoxin shock. J. Clin. Biochem. Nutr., 1, 165-170.

11. Yoshikawa, T., Murakami, M., Yoshida, N., Seto, O., and Kondo, M. (1983): Effects of superoxide dismutase and catalase on disseminated intravascular coagulation in rats.

Vol. 10, No. 3, 1991 
Thromb. Haemost., 50, 869-872.

12. Taniguchi, K., and Takanaka, K. (1984): Inhibitory effect of various drugs on phorbol myristate acetate and $n$-formyl-methionyl-leucyl-phenylalanine induced superoxide production in polymorphonuclear leukocytes. Biochem. Pharmacol., 33, 3159-3169.

13. Yoshikawa, T., Naito, Y., Takahashi, S., Tanigawa, T., Oyamada, H., Ueda, S., Takemura, T., Sugino, S., and Kondo, M. (1989): Influences of anti-allergic drugs on superoxide generation from the hypoxanthine-xanthine oxidase system or polymorphonuclear leukocytes. Allergy, 38, 486-492.

14. Oyanagui, Y. (1978): Inhibition of superoxide anion production in non-stimulated guinea pig peritoneal exudate cells by anti-inflammatory drugs. Biochem. Pharmacol., 27, 777-782.

15. Kaplan, H.B., Edelson, H.S., Korchak, H.M., Given, W.P., Abramson, S., and Weissmann, G. (1984): Effects of non-steroidal anti-inflammatory agents on human neutrophil functions in vitro and in vivo. Biochem. Pharmacol., 33, 371-378.

16. Niwa, Y., and Miyachi, Y. (1986): Antioxidant action of natural health products and Chinese herbs. Inflammation, 10, 79-91.

17. Uchida, S., Edamatsu, R., Hiramatsu, M., Mori, A., Nonaka, G., Nishioka, I., Niwa, M., and Ozaki, M. (1987): Condensed tannins scavenge active oxygen free radicals. Med. Sci. Res., 15, 831-832.

18. Yoshikawa, T., Takahashi, S., Naito, Y., Tanigawa, T., Ueda, S., Oyamada, H., Sugino, S., and Kondo, M. (1990): Influences of traditional Chinese medicines on oxygen-derived free radicals. J. Clin. Exp. Med., 152, 741-742.

19. Yoshikawa, T., Yoshida, N., Naito, Y., Takemura, T., Miyagawa, H., Tanigawa, T., and Kondo, M. (1990): Role of oxygen radicals in the pathogenesis of gastric mucosal lesions induced by water-immersion restraint stress and burn stress in rats. J. Clin. Biochem. Nutr., 9, 269-278.

20. Yoshida, N., Yoshikawa, T., Ando, T., Naito, Y., Oyamada, H., Takemura, T., Tanigawa, T., Sugino, S., and Kondo, M. (1989): Pathogenesis of platelet-activating factor-induced gastric mucosal damage in rats. Scand. J. Gastroenterol., 24, Suppl. 162, 210-214.

21. Itoh, M., and Guth, P.H. (1985): Role of oxygen-derived free radicals in hemorrhagic shock-induced gastric lesion in rats. Gastroenterology, 88, 1162-1167.

22. Ohkawa, H., Ohishi, N., and Yagi, K. (1979): Assay for lipid peroxides for animal tissue by thiobarbituric acid reaction. Anal. Biochem., 95, 351-358.

23. Shepherd, A.P., and Riedel, G.L. (1982): Continuous measurement of intestinal mucosal blood flow by laser Doppler velocimetry. Am. J. Physiol., 242, G668-672.

24. Miyagawa, H., Yoshikawa, T., Tanigawa, T., Yoshida, N., Sugino, S., and Kondo, M. (1988): Measurement of serum superoxide dismutase activity by electron spin resonance. $J$. Clin. Biochem. Nutr., 5, 1-7.

25. Tanigawa, T. (1990): Determination of hydroxyl radical scavenging activity by electron spin resonance. J. Kyoto Pref. Univ. Med., 99, 133-143.

26. Kamata, T., Ohbuchi, N., Nakatani, M., Kobayashi, T., Hiratani, S., and Kobayashi, K. (1984): The action of oriental herbal medicines in acute gastric mucosal blood flow. Excerpta Medica, Int. Congr. Ser., 93, 211-219.

27. Yoshikawa, T., Ueda, S., Takahashi, S., Naito, Y., Oyamada, H., Morita, Y., Tanigawa, T., Takemura, T., Sugino, S., and Kondo, M. (1990): Role of free radicals and lipid peroxidation in gastric mucosal injury induced by ischemia-reperfusion in rats. Jpn. J. Gastroenterol., 87, 8-15.

28. Erben-Russ, M., Bors, W., and Saran, M. (1987): Reactions of linoleic acid peroxyl radicals with phenolic antioxidants.-A pulse radiolysis study. Int. J. Radiat. Biol., 52, 393-412.

29. Bors, W., and Saran, M. (1987): Radical scavenging by flavonoid antioxidants. Free Rad. Res. Comm., 2, 289-294.

30. Abe, H. (1985): Effect of saikosaponins-d on aminonucleoside nephrosis. Jpn. J. Pharmacol., 38, 221-225. 